\title{
A distinct reed bunting dawn song and its relation to extrapair paternity
}

\author{
Stefan M. Suter*, David Ermacora, Nadia Rieille, Dietrich R. Meyer \\ Unit for Ecology and Evolution, Department of Biology, University of Fribourg
}

\begin{abstract}
Keywords: dawn chorus dawn song Emberiza schoeniclus extrapair paternity honest signal reed bunting sexual selection song diversity song rate song type

Elaborate birdsong is thought to have evolved under sexual selection. Extrapair mating can enforce sexual selection and thus the selection of song traits. We investigated song rate and song diversity, two song traits previously shown to be under sexual selection, in relation to paternity success in the reed bunting, Emberiza schoeniclus, a species with high levels of extrapair paternity. We focused our investigations on songs sung during the dawn chorus because singing at dawn is likely to be an honest signal and there is increasing evidence that females engage in extrapair copulations early in the morning. We classified a previously denoted continuous song, which is mainly sung during the dawn chorus, as a new song type in this species. Males with high song rate and high song diversity were more likely to gain extrapair paternity. These two song traits were also positively related to the number of extrapair offspring sired. However, most of the variance in extrapair paternity success was explained by age. Old males sired significantly more extrapair young than young males. Possibly, the new song type plays an important role in the female choice of extrapair mates. Reed bunting females may prefer males that sing at high rates and with high diversity because this indicates high phenotypic and genetic quality. Alternatively, these song parameters may be linked to other sexually selected traits or be important in the intersexual competition for extrapair fertilizations.
\end{abstract}

Sexual selection is thought to be the main force that drives the evolution of birdsong (Darwin 1871; Catchpole \& Slater 1995). Comparative data and experiments have shown that birdsong plays an important role in male-male competition and in female choice (Collins 2004). In socially monogamous passerine species, female choice is often not limited to the choice of a social partner because of extrapair mating (Griffith et al. 2002). Extrapair paternity (EPP) can increase the variance in reproductive success of males (Webster et al. 1995, 2007; Møller 1998; Albrecht et al. 2007; but see Freeman-Gallant et al. 2005; Whittingham \& Dunn 2005) and thus the selection pressure on sexually selected traits, such as song output or song diversity (Dolan et al. 2007). Studies on various bird species suggest that song is important in extrapair mate choice (Hasselquist et al. 1996; Kempenaers et al. 1997; Forstmeier et al. 2002; Byers 2007; Gil et al. 2007). However, other studies have found no relation between song and EPP (Buchanan \& Catchpole 2000; reviewed in Garamszegi \& Møller 2004). To be adaptive, a song trait must be recognized as an honest signal by the receiver and it must increase the reproductive success of its bearer. An honest signal is a costly signal indicating the quality of its producer

\footnotetext{
* Correspondence: S. Suter, University of Fribourg, Chemin du Musée 10, CH-1700 Fribourg, Switzerland.

E-mail address: stefan.suter@unifr.ch (S.M. Suter).
}

(Andersson 1994; Zahavi \& Zahavi 1997; Gil \& Gahr 2002). Elaborate song could be an honest signal indicating heterozygosity (Marshall et al. 2003; Reid et al. 2005), parasite resistance (Garamszegi et al. 2005) or past developmental stress (Buchanan et al. 2003).

Reed buntings, Emberiza schoeniclus, show one of the highest frequencies of EPP within passerine bird species (Dixon et al. 1994; Griffith et al. 2002) and they have a relatively elaborate song compared to other species of the genus Emberiza (Catchpole \& McGregor 1985). The reed bunting is therefore a suitable species to investigate the relation between song traits and female choice of extrapair mates. Previous studies on reed bunting song showed that males sing two song types: unpaired males sing a rapid song (type I) while paired males sing a slow song (type II; Nemeth 1996). Nemeth (1996) mentioned that type II song is sometimes performed continuously and here we classified this continuous song as a third song type (type III; Fig. 1). Type III song is mainly produced during the dawn chorus. Song output early in the morning is likely to be an honest signal, indicating a male's physical condition, because the birds could not feed during the night (Cuthill \& MacDonald 1990; Thomas \& Cuthill 2002; Barnett \& Briskie 2007). Studies on various species have found a peak in the dawn song activity or intensity during the fertile period of females (Mace 1987; Eens et al. 1994; Welling et al. 1995). It is also known from several bird species that copulations take place early in the morning 


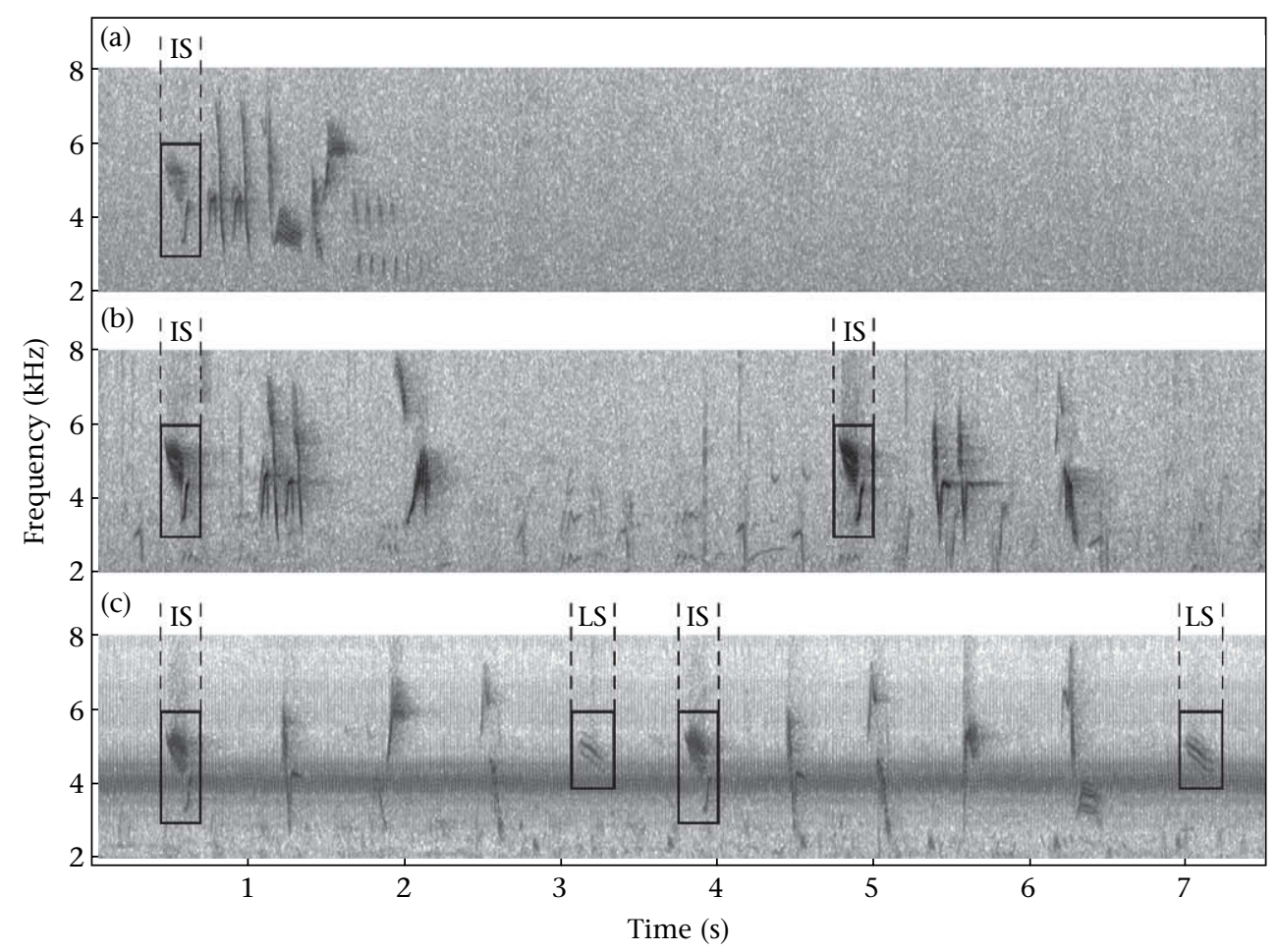

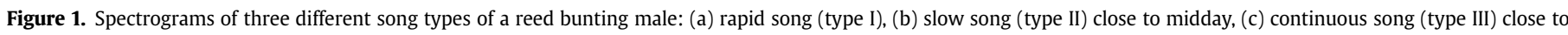
dawn. Song strophes in the type III song are often linked with a particular linking syllable (LS). This male uses the specific introductory syllable (IS).

(reviewed in Mace 1987; Birkhead \& Møller 1992). In the superb fairy-wren, Malurus cyaneus, females also actively engage in extrapair mating just before dawn (Double \& Cockburn 2000). Significant positive relationships between dawn song characteristics and EPP have been reported (Poesel et al. 2006; Dalziell \& Cockburn 2007; Sexton et al. 2007). We therefore focused our investigations on type III song produced during the dawn chorus. The aim of this study was to find out whether song rate and song diversity are related to extrapair paternity in this species. We would expect the relatively complex song of the reed bunting, compared to that of other species of the genus Emberiza, to have evolved and to be maintained by a strong female preference for extrapair mates with elaborate song.

\section{METHODS}

\section{Study Species}

The reed bunting is a small (ca. $19 \mathrm{~g}$ ), sexually dimorphic passerine species. The predominant breeding system is social monogamy with high rates of extrapair paternity (O'Malley 1993). Pairs normally raise two broods per breeding season, which lasts from the end of April to the end of July. Reed buntings perform a distinct dawn chorus where males sing loudly and persistently. A song strophe consists of a series of three to seven syllables: an introductory syllable, multiple syllables, and sometimes a final trill (Fig. 1). It lasts 1-4 s with a frequency range of $2-8 \mathrm{kHz}$. Males use a repertoire of 10-30 syllables and often start their song strophe with specific introductory syllables (Snow 1994; Nemeth 1996). Females are able to identify individual singers (Nemeth 1994).

\section{Study Site and General Field Methods}

We conducted the fieldwork during 2004, 2005 and 2006 on the marshland Grande Cariçaie at the Lake of Neuchâtel near Gletterens $\left(46^{\circ} 54^{\prime} 30^{\prime \prime} \mathrm{N}, 6^{\circ} 56^{\prime} 00^{\prime \prime} \mathrm{E}\right)$ in Switzerland. The vegetation of the 33 ha study site is dominated by dense stands of sedges, Carex elata, and fen-sedges, Cladium mariscus, mixed with reed, Phragmites australis (Aebischer et al. 1996; Keiser 2007). For orientation, a grid of $50 \times 50 \mathrm{~m}$ was laid over the study area. From the end of April we systematically searched for nests, mapped them and monitored them daily to assign the exact hatching date. However, some broods were only found after hatching. Adult birds were mist-netted either at the nest site or (for some males) with the help of playback near their songposts. Birds were ringed with a unique combination of three colour rings and a numbered aluminium ring from the Swiss Ornithological Institute. From all birds we took about 5-50 $\mu$ l blood from the brachial or leg vein for parental analysis. Blood samples were collected in a $70 \mu \mathrm{l}$ capillary tube, put on ice in the field and stored at $-18{ }^{\circ} \mathrm{C}$ on the same day. Dead nestlings and eggs that failed to hatch were collected. The social parents of a brood were identified at the nest site by direct observation or with the help of a colour video camera installed at the nest. Access to nature reserves was granted by the canton of Fribourg. The birds were caught and ringed under licence of the Federal Office for the Environment and blood samples were taken under licence of the cantonal ethics committee on animal experiments.

\section{Molecular Methods}

DNA was extracted from blood and tissue samples using a Peqgold blood DNA isolation kit (Peqlab, Erlangen, Germany). For paternity analyses we used fluorescently labelled primers for six different variable microsatellite loci: Esc $\mu 1$, Esc $\mu 3$, Esc $\mu 4$, Esc $\mu 6$ (Hanotte et al. 1994), Pdou5 (Griffith et al. 1999) and Ppi2 (Martinez et al. 1999). They were amplified by polymerase chain reaction (PCR) and products were run on an ABI PRISM 310 Genetic Analyzer (Applied Biosystems Inc., Foster city, CA, U.S.A). The alleles were determined with DNA fragment analysis software (Genescan version 3.1, Applied Biosystems). The combined exclusion 
probability of the six microsatellites was higher than 0.995 for the first parent and 0.999 for the second parent using the program CERVUS version 3.0 (Marshall et al. 1998; Kalinowski et al. 2007).

\section{Song Recording and Analysis}

Song was recorded from March to July using a Sennheiser ME 66/K6 directional microphone connected to a Sony WM-DC6 professional Walkman. For each recording we noted time, date and position on a map. We focused our recording effort on the dawn chorus, which starts about 40 min before civil twilight begins and disintegrates as daylight intensity increases. Civil twilight is defined to begin in the morning, and to end in the evening, when the centre of the sun is geometrically 6 degrees below the horizon (Seidelmann 1992). It is the limit at which twilight illumination is sufficient, under good weather conditions, for terrestrial objects to be clearly distinguished (Seidelmann 1992). We also made recordings during the day where singers could be identified by their ring colour code. The repertoire, introductory syllables and position of the singer allowed us to assign dawn chorus recordings to individual males.

Recordings were digitized into Raven 1.2.1 (Cornell Laboratory of ornithology, Ithaca, NY, U.S.A.) on a Macintosh G5 OS X and saved as Wav-files using the following parameters: input sample rate $44100 \mathrm{~Hz}$, sample format $16 \mathrm{bit}$, at normal speed, rate conversion decimation factor 2, output sample rate $22050 \mathrm{~Hz}$. Sonagrams were produced in Raven 1.2.1 with the following parameters: type Hann, time grid overlap $50 \%$. Syllables were determined by visual inspection. We followed Nemeth (1996) for the definition of a syllable. Songs were categorized by eye as continuous songs (type III) when pauses between song strophes were no longer than pauses between syllables; otherwise they were categorized as slow songs (type II). Rapid songs (type I) were excluded from the analysis. For the analysis we only used songs recorded between 20 April and 30 June, when fertile females were present on the study site. The peak of the song rate was determined with recordings made between 50 min before and 50 min after civil twilight began. For the analysis of song traits and extrapair paternity success we used means of the male's song type III recorded between 30 min before and 30 min after the song peak.

\section{Statistics}

Song rate, repertoire and song diversity were calculated from 100 consecutive syllables. Song rate is the number of syllables/s; repertoire is the number of different syllables; song diversity was calculated with Simpson's diversity index, formerly used to measure species diversity (Simpson 1949). The index takes into account the number of different syllables and the relative abundance of each syllable. Although the syllables in the reed bunting song are not independent of each other, we used Simpson's index because it gives a simple estimate of song diversity. We did not use repertoire in the analysis of paternity success because of the low repeatability.

We had data on song traits and reproductive success for 57 different males. For eight males we had data from 2 years and for three males data from 3 years (2004: 12 males; 2005: 25 males; 2006: 34 males). We pooled data over the 3 years by randomly choosing the data of 1 year for males that occurred in more than 1 year. The relationship between song traits and extrapair paternity was investigated in three ways. First, we compared song traits of males that sired extrapair young (EPY) with those of males that did not sire EPY. Second, we looked for a bivariate relation between song traits and the number of extrapair offspring a male sired. Third, we determined the relative effects of the song traits on EPP success taking into account male age in a general linear model
(GLM). Males were categorized as old males when they were at least in their second breeding season (2005: $N=10,2006: N=13$ ). We assumed unringed adults that were breeding for the first time on our study area in $2005(N=16)$ and $2006(N=21)$ to be young males (following Bouwman et al. 2007). Year was excluded from the final GLMs as it showed no effect in the initially expanded models. We also compared song traits between cuckolded males and the corresponding extrapair males in a pairwise test. Each male was only included once in this paired test with the corresponding extrapair male that sired most EPY. For statistical analysis we used JMP version 5.0.1 (SAS Institute Inc. Cary, NC, U.S.A.), R version 2.4.1 ( $\mathrm{R}$ Foundation for Statistical Computing, Vienna, Austria) and EXCEL. Nonparametric tests were used for non-normally distributed data. All tests are two tailed with a significance level of $P<0.05$.

\section{RESULTS}

\section{Repeatability and Correlations Between Song Traits}

The repeatability (Lessells \& Boag 1987) of the three song traits was highest for song rate (repeatability of song rate: $F_{36,63}=2.96$, $r=0.42, P=0.0001$; repertoire: $F_{36,63}=1.68, r=0.20, P=0.0351$; diversity: $\left.F_{36,63}=2.59, r=0.37, P=0.0005\right)$. The three song traits were positively correlated with each other (repertoire versus song rate: $r_{56}=0.24, P<0.07$; song diversity versus song rate: $r_{56}=0.34, P<0.01$; song diversity versus repertoire: $r_{56}=0.70$, $P<0.001)$.

\section{Frequency and Distribution of Extrapair Paternity}

We genotyped 540 offspring from 143 broods (2004: 147 offspring from 38 broods; 2005: 209 offspring from 56 broods; 2006: 184 offspring from 49 broods). The social father was determined for 506 offspring from 132 broods and the genetic father for 529 offspring from 142 broods. On average, there were 39\% EPY and $64 \%$ of the broods contained at least one EPY. In 2005 there were significantly more EPY than in the other years (2004: 46/139; 2005: 91/199; 2006: 61/168; likelihood ratio test: $\left.G_{2}=6.3, P=0.05\right)$. The EPY were not equally distributed among broods: there were 48 entire within-pair broods, 60 mixed broods and 24 entire extrapair broods. In each year, the distribution of EPY among broods differed from that expected under a binomial distribution (likelihood ratio test: all $P<0.01$ ). In 73 broods a single male sired EPY and in 11 broods the EPY were sired by two different males. Males significantly increased their reproductive success with extrapair paternity (Table 1).

\section{Song Traits, Age and Extrapair Paternity}

Song rate reached a peak shortly before civil twilight (Fig. 2). Song strophes in the type III song had characteristic male-specific introductory syllables and a linking syllable (Fig. 1). At least $91 \%$ $(52 / 57)$ of the males used the linking syllable in their song. Song

\section{Table 1}

Reproductive success of reed bunting males that did or did not gain extrapair paternity (EPP)

\begin{tabular}{lllll}
\hline Year & Gained EPP & Did not gain EPP & $Z^{*}$ & $P$ \\
\hline 2004 & $9.2 \pm 1.5(6)$ & $4.0 \pm 1.5(6)$ & 1.70 & 0.089 \\
2005 & $7.8 \pm 1.1(16)$ & $3.0 \pm 1.4(9)$ & 2.68 & 0.007 \\
2006 & $7.8 \pm 0.7(15)$ & $2.3 \pm 0.6(19)$ & 4.01 & 0.0001 \\
Pooled & $8.1 \pm 0.7(28)$ & $2.3 \pm 0.7(29)$ & 4.80 & 0.0001 \\
\hline
\end{tabular}

The mean number of offspring $\pm \mathrm{SE}$ and sample size (in parentheses) are shown. * Wilcoxon two-sample test. 


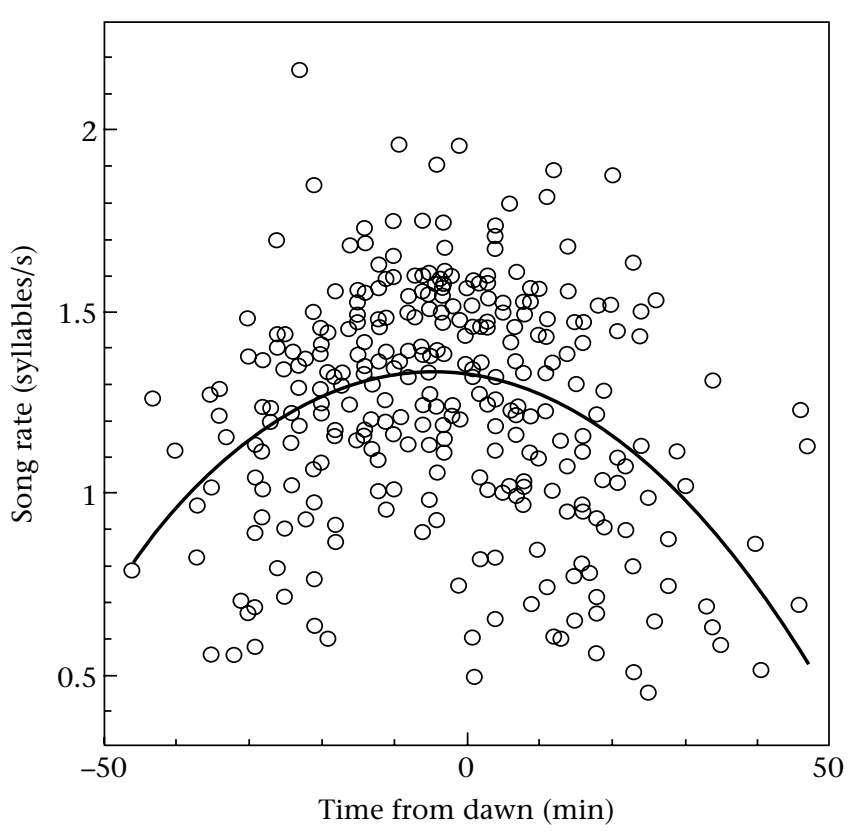

Figure 2. The song rate of reed buntings in relation to the beginning of civil twilight (dawn). The song rate reached a peak 4.4 min before dawn $(Y=1.3316-0.002701$ $X-0.000305 X^{2}, R=0.3964$ ). The analysis includes 311 recordings of 64 different males, recorded between 20 April and 30 June over 3 years (2004-2006).

rate, repertoire and diversity were all significantly higher in type III than type II song (Table 2).

Males that sang at a high rate during the dawn chorus were more likely to gain extrapair paternity than males that sang at a low rate (logistic regression: $\chi_{1}^{2}=6.12, P=0.02$; Fig. $3 a$ ) and males with high song diversity were more likely to gain extrapair paternity than males with low song diversity $\left(\chi_{1}^{2}=5.63, P=0.02\right.$; Fig. $\left.3 \mathrm{~b}\right)$. We found positive correlations between song rate/diversity and the number of EPY a male sired (Fig. 4).

Old males sired significantly more EPY than young males (mean $\mathrm{EPY} \pm \mathrm{SE}$ of old males: $3.33 \pm 0.49, \quad N=18$; young males: $0.94 \pm 0.37, \quad N=33$; Wilcoxon two-sample test: $Z=3.81$, $P=0.0001)$. GLMs showed that song diversity but not song rate had a significant effect on extrapair paternity success, that is, on the number of EPY sired, when age was taken into account (Table 3). Males that returned in a subsequent year increased their song repertoire (Wilcoxon signed-ranks test: $Z=-2.47, N=11, P=0.01$ ) and song diversity $(Z=-2.11, N=11, P=0.04)$. Song rate of individual males did not change significantly between consecutive years $(Z=0.16, N=11, P=0.87)$.

Mean song rate, mean diversity and the mean number of EPY of males did not differ between years (mean song rate: ANOVA: $F_{2,68}=1.00, P=0.37$; mean song diversity: Kruskal-Wallis test: $H_{2}=0.27, P=0.87$; mean number of EPY: $H_{2}=2.40, P=0.30$ ). Pooled data over the 3 years revealed no significant difference in the mean song rate between males that were and those that

Table 2

Paired comparisons of song traits $\bar{X} \pm$ SE between type II and type III song

\begin{tabular}{lllrl}
\hline Song trait & Type II & Type III & \multicolumn{1}{l}{$t_{49}{ }^{*}$} & $P$ \\
\hline Song rate (syllables/s) & $0.96 \pm 0.03$ & $1.49 \pm 0.02$ & 17.96 & 0.0001 \\
Repertoire & $6.23 \pm 0.26$ & $7.24 \pm 0.21$ & 3.76 & 0.0005 \\
Song diversity & $0.75 \pm 0.01$ & $0.80 \pm 0.01$ & 5.48 & 0.0001
\end{tabular}

The song traits were calculated from 100 consecutive syllables. The repertoire is the number of different syllables that appeared. The song diversity was calculated using Simpson's diversity index.

* Paired $t$ test.
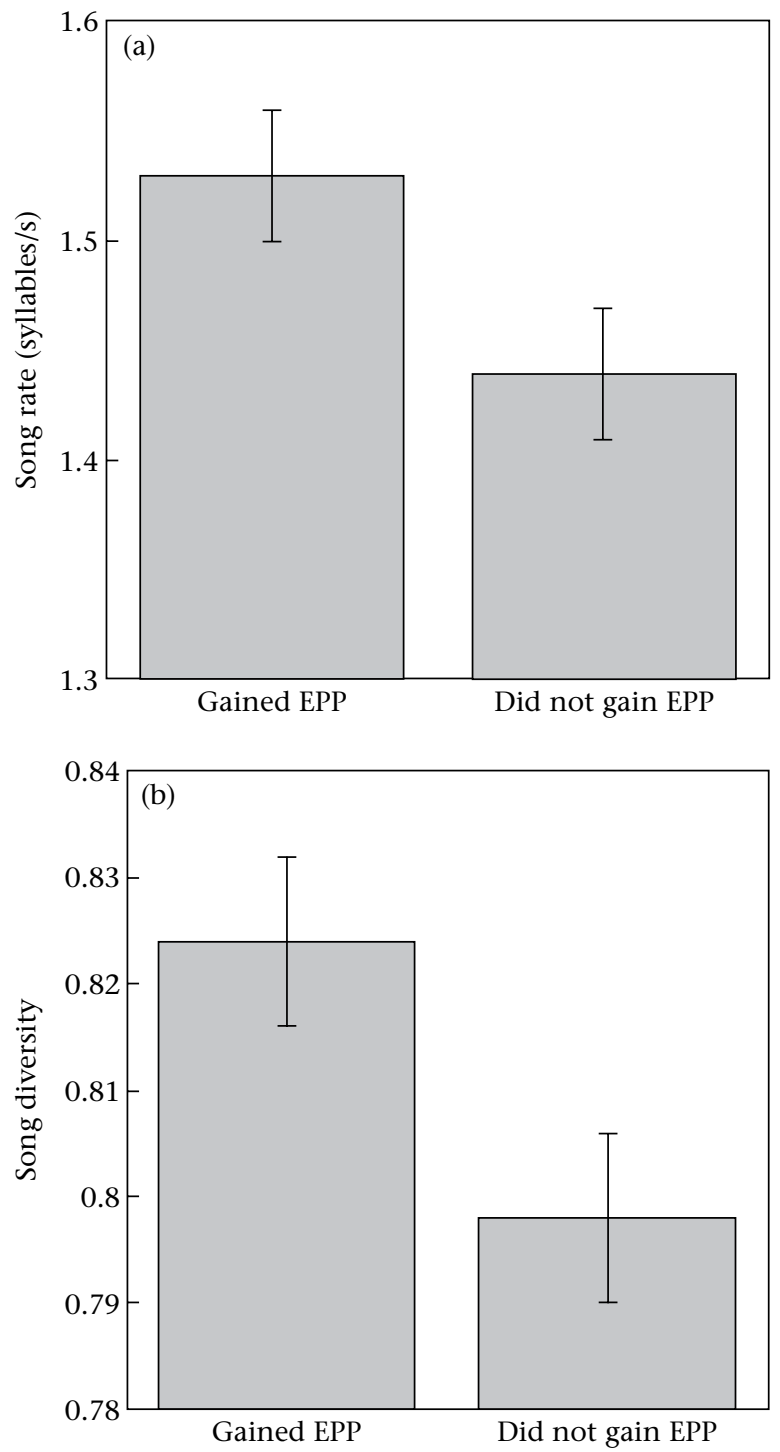

Figure 3. Mean $\pm \mathrm{SE}$ (a) song rate and (b) song diversity of reed bunting males that did $(N=28)$ or did not $(N=29)$ gain extrapair paternity (EPP). The age categories of males were combined.

were not cuckolded (mean song rate (syllables/s) \pm SE of cuckolded males: $1.47 \pm 0.02, \quad N=40$; not cuckolded males: $1.53 \pm 0.04, \quad N=17$; logistic regression: $\chi_{1}^{2}=1.68, \quad P=0.20$ ). Mean song diversity showed a nonsignificant tendency to be higher in males that were not cuckolded than in males that were cuckolded (mean song diversity $\pm \mathrm{SE}$ of cuckolded males: $0.804 \pm 0.006, \quad N=40$; not cuckolded males: $0.826 \pm 0.010$, $N=17$; logistic regression: $\left.\chi_{1}^{2}=3.27, P=0.07\right)$. A paired test between an extrapair male and the associated cuckolded male revealed no significant difference in song rate and song diversity (song rate: paired $t$ test: $t_{30}=0.631, P=0.53$; song diversity: $t_{30}=1.57, P=0.13$ ).

\section{DISCUSSION}

Elaborate birdsong is thought to have evolved under sexual selection (Darwin 1871; Catchpole \& Slater 1995). Our detection of a particular song type that reed bunting males mainly sing during the dawn chorus allowed us to ask questions about its signalling function. In our study, reed bunting males increased significantly the number of genetic offspring through EPP (Table 1). We found positive relationships between two dawn song characteristics 


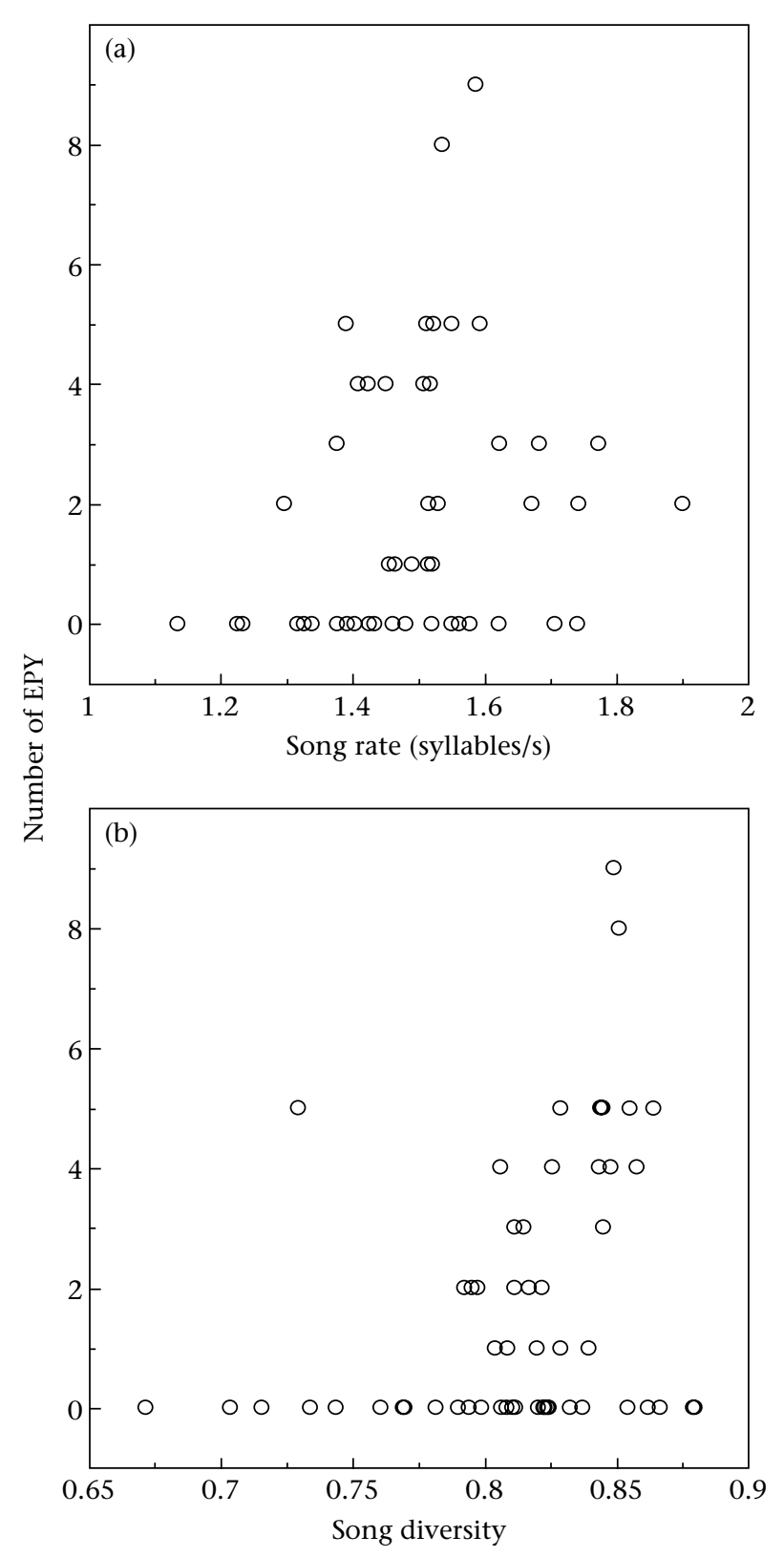

Figure 4. (a) Mean song rate of reed bunting males in relation to the number of extrapair young (EPY) sired $\left(r_{\mathrm{S}}=0.268, N=57, P=0.04\right)$. (b) Mean song diversity in relation to the number of EPY sired $\left(r_{\mathrm{S}}=0.372, N=57, P=0.01\right)$. Data were pooled over 3 years (2004-2006) where each male is only included once. The age categories of males were combined.

(song rate, song diversity) and EPP success (Figs 3, 4). Experiments on other bird species have shown that these two song traits may indeed be under sexual selection (Draganoiu et al. 2002; Spencer et al. 2005). In other studies the onset of dawn song, song rate or consistent singing at dawn were positively related to EPP (Poesel et al. 2006; Byers 2007; Dolan et al. 2007).

Reed bunting males sing different song types (Fig. 1). The function of type I song may be the attraction of a social partner and the defence of potential breeding sites against other males (Ewin 1977). We observed that paired males sometimes also sing type I song later in the season. Since a few males are socially polygynous, paired males may keep on singing type I song to attract additional females. The slow type II song peaks in intensity during the incubation period of the social female (Nemeth 1996). Incubating reed bunting females are more likely to leave the nest and to stay away
Table 3

General linear models (GLMs) showing the relative effects of song rate, song diversity and age on extrapair paternity success, that is, the number of extrapair young a reed bunting male sired

\begin{tabular}{llrlr}
\hline & Variable & \multicolumn{1}{c}{$F_{1,50}$} & \multicolumn{1}{c}{$P$} & \multicolumn{1}{c}{$\mathrm{Eta}^{2}$} \\
\hline GLM (Song rate and age) & Age & 11.68 & 0.001 & 0.188 \\
& Song rate & 0.41 & 0.524 & 0.004 \\
& Age*song rate & 0.01 & 0.913 & $<0.001$ \\
GLM (Song diversity and age) & Age & 11.70 & 0.001 & 0.166 \\
& Song diversity & 6.91 & 0.012 & 0.098 \\
& Age*song diversity & 1.85 & 0.179 & 0.026 \\
\hline
\end{tabular}

$\mathrm{Eta}^{2}$ : relative effect size is the proportion of the variance explained by the variable.

for longer when their social male is singing and Wingelmaier et al. (2007a) suggested the type II song is an 'all-clear' signal to the incubating female. Type III song peaks in intensity during the fertile period of the females. From observations in aviaries it is known that female reed buntings initiate extrapair copulations towards singing males (Wingelmaier et al. 2007b) and there is evidence from another species that extrapair copulations take place early in the morning (Double \& Cockburn 2000). It might be easier for females to engage in extrapair mating at dawn because at that time of day mate guarding is hindered by low visibility and because the social male is occupied with singing and attracting extrapair mates himself. However, a trade-off between mate guarding and extrapair mate attraction may only occur when breeding synchrony is high (Weatherhead \& Yezerinac 1998).

Extrapair mates are mostly neighbouring males (Suter et al. 2007). Females may thus be able to estimate the quality of these males throughout the breeding season. Females can more easily compare the songs of different males early in the morning because all males then sing simultaneously (Mennill et al. 2002; Poesel et al. 2004). In addition, songs are loud and clear at dawn because of the temperature inversion that forms a tunnel of cold air, there is little or no wind, and little environmental noise (Slabbekoorn 2004). For males, however, dawn singing is costly. Depending on environmental temperature, males lose $5-10 \%$ of their body mass at night because they do not feed (Helms 1963; S.M. Suter, unpublished data). In addition, persistent singing takes time and energy (Thomas 2002; Ward et al. 2003; Ward \& Slater 2005; Hasselquist \& Bensch 2008) and increases the risk of being taken by a predator (Møller et al. 2006). Despite this, the reed bunting dawn chorus is loud and lasts for about $1 \mathrm{~h}$. Thus only males in good physical condition may maintain a high song rate during this time (Cuthill \& MacDonald 1990; Thomas \& Cuthill 2002; Barnett \& Briskie 2007). A high song rate at dawn could thus be an honest signal towards females, indicating male quality (Otter et al. 1997).

We found a positive relation between song diversity and EPP (Figs 3, 4, Table 3). Sexual selection theory suggests that a more complex song has additional costs, which only the best males can afford (Catchpole 1987; Catchpole \& Slater 1995). More complex songs may need more brain space and an additional investment in neurons (Airey \& DeVoogd 2000; Airey et al. 2000; Jarvis 2004). Several studies have shown a female preference for males with higher song diversity (Catchpole 1980; Hasselquist et al. 1996; Mountjoy \& Lemon 1996; Pasteau et al. 2004; Reid et al. 2004). However, neither song diversity nor temporal song output was related to levels of extrapair paternity in comparative analyses within and between species (Garamszegi \& Møller 2004). Song rate and song diversity were intercorrelated in our study. Only experiments where females can choose between different manipulated songs can help to disentangle the relative importance of the two song traits in the choice of extrapair mates. The positive correlations between song traits and EPP success indicate a possible relation, but they are not proof that female reed buntings choose 
males with elaborate song for extrapair copulations. Possibly, song characteristics are correlated with other sexually selected traits such as plumage coloration. Alternatively, song characteristics at dawn could be important in male-male interactions (Liu \& Kroodsma 2007) that may determine the outcome of extrapair fertilizations. Experiments and the application of new technologies such as high-resolution tracking in time and space should help to bridge our gaps in knowledge.

Song rate and song diversity during the dawn chorus were not related to paternity success in the male's own nest. Other studies have also found no relation between within-pair mating success and song characteristics (Krokene et al. 1996; Poesel et al. 2006; Dolan et al. 2007; but see Leisler et al. 2000). It is also not likely that type III song plays a role in the defence of food resources because reed buntings forage mostly outside their territories (Keiser 2007).

An earlier study on reed buntings showed that older males sing actively during the day and are more successful at gaining EPP (Bouwman et al. 2007). In our study too, old males were more successful at gaining EPP than young males (Table 3 ). A paired test revealed that males increased their repertoire, and thus song diversity, between successive years. Other studies on various bird species showed that the repertoire increases with age or at least between the first two breeding seasons (Nottebohm \& Nottebohm 1978; Hiebert et al. 1989; Lampe \& Espmark 1994; Gil et al. 2001; Forstmeier et al. 2006; Kiefer et al. 2006; Nicholson et al. 2007). A large repertoire and high song diversity may thus reflect male age and indirectly indicate good genes that enabled the male to survive (Kokko \& Lindstrom 1996; Kokko 1998; Brooks \& Kemp 2001; Jennions et al. 2001).

A positive relation between song output and breeding density has been found in other species (Sexton et al. 2007) as well as between breeding density and the occurrence of EPP (Westneat \& Sherman 1997; Petrie \& Kempenaers 1998). However, local breeding density was not correlated with the occurrence of EPP in reed buntings (Bouwman 2005; Keiser 2007).

Females may choose males with elaborate song for extrapair copulations because it indicates male viability and thus good genes (Birkhead \& Møller 1992; Hasselquist et al. 1996). In the reed bunting population we studied, extrapair fledglings were more heterozygous and survived at a higher rate than within-pair fledglings (Suter et al. 2007). The high heterozygosity of the extrapair young (EPY) was based on a low genetic similarity between females and extrapair males (Suter et al. 2007). These earlier findings support the genetic compatibility hypothesis and may explain the extrapair mating behaviour of females (Suter et al. 2007). Females may estimate the genetic dissimilarity of a male through song characteristics. However, the choice would then focus on relative song characteristics and depend on the genotype of the individual female. Females can increase the heterozygosity of their offspring not only when mating with genetically dissimilar males but also when mating with more heterozygous males (Mitton et al. 1993). A male could indicate his heterozygosity through absolute values of song rate or song diversity. However, in our study the successful extrapair males were not more heterozygous than the unsuccessful but potential extrapair males (Suter et al. 2007) and song rate and song diversity were not related to a male's heterozygosity (S.M. Suter, unpublished data).

Female reed buntings may gain no genetic benefits from being attracted to extrapair males with high song rate and diversity or these song traits may only play a role in intrasexual competition. If so, females may even do better to ignore absolute song traits when choosing genetically compatible mates. On the other hand, females may additionally profit through extrapair matings with compatible males that show elaborate song traits because they could get, at the same time, both good and compatible genes for their offspring. Benefits of extrapair fertilization can be based on both good and compatible genes, as they are not mutually exclusive (Neff \& Pitcher 2005). Female choice could then be separated into two steps. First, females copulate with 'good singers' to obtain good genes. Second, within the female's reproductive tract, a subsequent cryptic female choice (Birkhead \& Pizzari 2002) could take place, where sperm of 'good singers' are selected for compatibility. The relative importance of the two indirect genetic benefits may depend on the current genetic set-up of the population and change over time (Neff \& Pitcher 2005). Whether she goes for compatible or for good genes may also depend on a female's genotype (Kempenaers 2007). For example, a highly heterozygous female could profit more by mating with males that indicate good genes whereas a female that has low genetic heterozygosity would profit more by engaging in extrapair copulations with a genetically dissimilar or more heterozygous male. In this scenario, different females would pursue different mating strategies within the same population. Additionally to these indirect genetic benefits, females might gain direct benefits such as fertilization assurance of the clutch (Wetton \& Parkin 1991; Lifjeld et al. 2007). 'Good singers' might indicate not only their excellent physical condition but also their ability to fertilize eggs (Sheldon 1994; but see Birkhead \& Fletcher 1995; Birkhead et al. 1997).

In conclusion, we found positive relations between two song characteristics (song rate, song diversity) of a distinct dawn song type and EPP success. The relatively complex song of the reed bunting, compared to that of other species of the genus Emberiza, and the distinct and persistent dawn chorus, may be the result of strong sexual selection during the choice of extrapair partners. The dawn chorus may be important in the context of extrapair mating in many other bird species as well. Further studies and experiments are needed to investigate the relative importance of genetic benefits based on good and compatible genes in the context of female promiscuity.

\section{Acknowledgments}

We are grateful to Joanna Bielańska, Vanessa Heierli, Manuel Lingg, Sabine Röthlin-Spillmann, Ludivine Strambini and Elham Tarbush for the help in the field and in the laboratory. We thank Louis-Félix Bersier and Thomas Clerc for statistical advice, Bart Kempenaers for helpful advice and two anonymous referees for helping us to improve the manuscript. Fieldwork was coordinated with Michel Antoniazza from the Groupe d'étude et de gestion de la Grande Cariçaie (GEG).

\section{References}

Aebischer, A., Perrin, N., Krieg, M., Studer, J. \& Meyer, D. R. 1996. The role of territory choice, mate choice and arrival date on breeding success in the Savi's warbler Locustella luscinioides. Journal of Avian Biology, 27, 143-152.

Airey, D. C. \& DeVoogd, T. J. 2000. Greater song complexity is associated with augmented song system anatomy in zebra finches. Neuroreport, 11, 2339-2344.

Airey, D. C., Buchanan, K. L., Szekely, T., Catchpole, C. K. \& DeVoogd, T. J. 2000 Song, sexual selection, and a song control nucleus (HVc) in the brains of European sedge warblers. Journal of Neurobiology, 44, 1-6.

Albrecht, T., Schnitzer, J., Kreisinger, J., Exnerova, A., Bryja, J. \& Munclinger, P. 2007. Extrapair paternity and the opportunity for sexual selection in longdistant migratory passerines. Behavioral Ecology, 18, 477-486.

Andersson, M. 1994. Sexual Selection. Princeton, New Jersey: Princeton University Press.

Barnett, C. A. \& Briskie, J. V. 2007. Energetic state and the performance of dawn chorus in silvereyes (Zosterops lateralis). Behavioral Ecology and Sociobiology, 61 579-587.

Birkhead, T. R. \& Fletcher, F. 1995. Male phenotype and ejaculate quality in the zebra finch Taeniopygia guttata. Proceedings of the Royal Society of London, Series $B, 262,329-334$

Birkhead, T. R. \& Møller, A. P. 1992. Sperm Competition in Birds. Evolutionary Causes and Consequences. London: Academic Press.

Birkhead, T. R. \& Pizzari, T. 2002. Postcopulatory sexual selection. Nature Reviews Genetics, 3, 262-273.

Birkhead, T. R., Buchanan, K. L., Devoogd, T. J., Pellatt, E. J., Szekely, T. \& Catchpole, C. K. 1997. Song, sperm quality and testes asymmetry in the sedge warbler. Animal Behaviour, 53, 965-971. 
Bouwman, K. M. 2005. The Illusion of monogamy. Patterns of extra-pair paternity in the reed bunting (Emberiza schoeniclus). Ph.D. thesis, University of Groningen.

Bouwman, K. M., Van Dijk, R. E., Wijmenga, J. J. \& Komdeur, J. 2007. Older male reed buntings are more successful at gaining extrapair fertilizations. Animal Behaviour, 73, 15-27.

Brooks, R. \& Kemp, D. J. 2001. Can older males deliver the good genes? Trends in Ecology \& Evolution, 16, 308-313.

Buchanan, K. L. \& Catchpole, C. K. 2000. Extra-pair paternity in the socially monogamous sedge warbler Acrocephalus schoenobaenus as revealed by multilocus DNA fingerprinting. Ibis, 142, 12-20.

Buchanan, K. L., Spencer, K. A., Goldsmith, A. R. \& Catchpole, C. K. 2003. Song as an honest signal of past developmental stress in the European starling (Sturnus vulgaris). Proceedings of the Royal Society of London, Series B, 270, 1149-1156.

Byers, B. E. 2007. Extrapair paternity in chestnut-sided warblers is correlated with consistent vocal performance. Behavioral Ecology, 18, 130-136.

Catchpole, C. K. 1980. Sexual selection and the evolution of complex songs among European warblers of the genus Acrocephalus. Behaviour, 74, 149-166.

Catchpole, C. K. 1987. Bird song, sexual selection and female choice. Trends in Ecology E' Evolution, 2, 94-97.

Catchpole, C. K. \& McGregor, P. K. 1985. Sexual selection, song complexity and plumage dimorphism in European buntings of the genus Emberiza. Animal Behaviour, 33, 1378-1380.

Catchpole, C. K. \& Slater, P. J. B. 1995. Bird Song: Biological Themes and Variations. Cambridge: Cambridge University Press.

Collins, S. 2004. Vocal fighting and flirting: the function of birdsong. In: Nature's Music: The Science of Birdsong (Ed. by P. Marler \& H. Slabbekoorn), pp. 39-79. San Diego: Elsevier.

Cuthill, I. C. \& MacDonald, W. A. 1990. Experimental manipulation of the dawn and dusk chorus in the blackbird Turdus merula. Behavioral Ecology and Sociobiology, 26, 209-216.

Dalziell, A. H. \& Cockburn, A. 2007. Dawn song in superb fairy-wrens: a bird that seeks extrapair copulations during the dawn chorus. Animal Behaviour, 75, 489-500.

Darwin 1871. The Descent of Man and Selection in Relation to Sex. London: Murray.

Dixon, A., Ross, D., Omalley, S. L. C. \& Burke, T. 1994. Paternal investment inversely related to degree of extra-pair paternity in the reed bunting. Nature, 371, 698-700.

Dolan, A. C., Murphy, M. T., Redmond, L. J., Sexton, K. \& Duffield, D. 2007. Extrapair paternity and the opportunity for sexual selection in a socially monogamous passerine. Behavioral Ecology, 18, 985-993.

Double, M. \& Cockburn, A. 2000. Pre-dawn infidelity: females control extra-pair mating in superb fairy-wrens. Proceedings of the Royal Society of London, Series B, 267, 465-470.

Draganoiu, T. I., Nagle, L. \& Kreutzer, M. 2002. Directional female preference for an exaggerated male trait in canary (Serinus canaria) song. Proceedings of the Royal Society of London, Series B, 269, 2525-2531.

Eens, M., Pinxten, R. \& Verheyen, R. F. 1994. Variation in singing activity during the breeding cycle of the European starling Sturnus vulgaris. Belgian Journal of Zoology, 124, 167-174.

Ewin, J. P. 1977. Physical and functional analysis of song in the reed bunting, Emberiza schoeniclus. Ph.D. thesis, University of London.

Forstmeier, W., Kempenaers, B., Meyer, A. \& Leisler, B. 2002. A novel song parameter correlates with extra-pair paternity and reflects male longevity. Proceedings of the Royal Society of London, Series B, 269, 1479-1485.

Forstmeier, W., Hasselquist, D., Bensch, S. \& Leisler, B. 2006. Does song reflect age and viability? A comparison between two populations of the great reed warbler Acrocephalus arundinaceus. Behavioral Ecology and Sociobiology, $\mathbf{5 9}$ 634-643.

Freeman-Gallant, C. R., Wheelwright, N. T., Meiklejohn, K. E., States, S. L. \& Sollecito, S. V. 2005. Little effect of extrapair paternity on the opportunity for sexual selection in Savannah sparrows (Passerculus sandwichensis). Evolution, 59, 422-430.

Garamszegi, L. Z. \& Møller, A. P. 2004. Extrapair paternity and the evolution of bird song. Behavioral Ecology, 15, 508-519.

Garamszegi, L. Z., Heylen, D., Møller, A. P., Eens, M. \& de Lope, F. 2005. Agedependent health status and song characteristics in the barn swallow. Behavioral Ecology, 16, 580-591.

Gil, D. \& Gahr, M. 2002. The honesty of bird song: multiple constraints for multiple traits. Trends in Ecology \& Evolution, 17, 133-141.

Gil, D., Cobbs, J. L. S. \& Slater, P. J. B. 2001. Song characteristics are age dependant in the willow warbler Phylloscopus trochilus. Animal Behaviour, 62, 689-694.

Gil, D., Slater, P. J. B. \& Graves, J. A. 2007. Extra-pair paternity and song characteristics in the willow warbler Phylloscopus trochilus. Journal of Avian Biology, $\mathbf{3 8}$, 291-297.

Griffith, S. C., Owens, I. P. F. \& Burke, T. 1999. Female choice and annual reproductive success favour less-ornamented male house sparrows. Proceedings of the Royal Society of London, Series B, 266, 765-770.

Griffith, S. C., Owens, I. P. F. \& Thuman, K. A. 2002. Extra pair paternity in birds: a review of interspecific variation and adaptive function. Molecular Ecology, 11, $2195-2212$

Hanotte, O., Zanon, C., Pugh, A., Greig, C., Dixon, A. \& Burke, T. 1994. Isolation and characterization of microsatellite loci in a passerine bird: the reed bunting Emberiza schoeniclus. Molecular Ecology, 3, 529-530.

Hasselquist, D. \& Bensch, S. 2008. Daily energy expenditure of singing great reed warblers Acrocephalus arundinaceus. Journal of Avian Biology, 39, 384-388.
Hasselquist, D., Bensch, S. \& vonSchantz, T. 1996. Correlation between male song repertoire, extra-pair paternity and offspring survival in the great reed warbler. Nature, 381, 229-232.

Helms, C. W. 1963. Tentative field estimates of metabolism in buntings. Auk, 80 318-334.

Hiebert, S. M., Stoddard, P. K. \& Arcese, P. 1989. Repertoire size, territory acquisition and reproductive success in the song sparrow. Animal Behaviour, 37, 266-273.

Jarvis, E. D. 2004. Brains and birdsong. In: Nature's Music: The Science of Birdsong (Ed. by P. Marler \& H. Slabbekoorn), pp. 226-271. San Diego: Elsevier.

Jennions, M. D., Møller, A. P. \& Petrie, M. 2001. Sexually selected traits and adult survival: a meta-analysis. Quarterly Review of Biology, 76, 3-36.

Kalinowski, S. T., Taper, M. L. \& Marshall, T. C. 2007. Revising how the computer program CERVUS accommodates genotyping error increases success in paternity assignment. Molecular Ecology, 16, 1099-1106.

Keiser, M. 2007. Habitat occupation strategies and breeding behaviour in reed buntings. Ph.D. thesis, University of Fribourg.

Kempenaers, B., Verheyren, G. R. \& Dhondt, A. A. 1997. Extrapair paternity in the blue tit (Parus caeruleus): female choice, male characteristics, and offspring quality. Behavioral Ecology, 8, 481-492.

Kempenaers, B. 2007. Mate choice and genetic quality: a review of the heterozygosity theory. Advances in the Study of Behavior, 37, 189-278.

Kiefer, S., Spiess, A., Kipper, S., Mundry, R., Sommer, C., Hultsch, H. \& Todt, D. 2006. First-year common nightingales (Luscinia megarhynchos) have smaller song-type repertoire sizes than older males. Ethology, 112, 1217-1224.

Kokko, H. 1998. Good genes, old age and life-history trade-offs. Evolutionary Ecology, 12, 739-750.

Kokko, H. \& Lindstrom, J. 1996. Evolution of female preference for old mates. Proceedings of the Royal Society of London, Series B, 263, 1533-1538.

Krokene, C., Anthonisen, K., Lifjeld, J. T. \& Amundsen, T. 1996. Paternity and paternity assurance behaviour in the bluethroat, Luscinia s. svecica. Animal Behaviour, 52, 405-417.

Lampe, H. M. \& Espmark, Y. O. 1994. Song structure reflects male quality in pied flycatchers, Ficedula hypoleuca. Animal Behaviour, 47, 869-876.

Leisler, B., Beier, J., Staudter, H. \& Wink, M. 2000. Variation in extra-pair paternity in the polygynous great reed warbler (Acrocephalus arundinaceus). Journal für Ornithologie, 141, 77-84.

Lessells, C. M. \& Boag, P. T. 1987. Unrepeatable repeatabilities: a common mistake. Auk, 104, 116-121.

Lifjeld, J. T., Laskemoen, T., Fossøy, F., Johnsen, A. \& Kleven, O. 2007. Functional infertility among territorial males in two passerine species, the willow warbler Phylloscopus trochilus and the bluethroat Luscinia svecica. Journal of Avian Biology, 38, 267-272.

Liu, W. C. \& Kroodsma, D. E. 2007. Dawn and daytime singing behavior of chipping sparrows (Spizella passerina). Auk, 124, 44-52.

Mace, R. 1987. The dawn chorus in the great tit Parus major is directly related to female fertility. Nature, 330, 745-746.

Marshall, R. C., Buchanan, K. L. \& Catchpole, C. K. 2003. Sexual selection and individual genetic diversity in a songbird. Proceedings of the Royal Society of London, Series B, 270, S248-S250.

Marshall, T. C., Slate, J., Kruuk, L. E. B. \& Pemberton, J. M. 1998. Statistical confidence for likelihood-based paternity inference in natural populations. Molecular Ecology, 7, 639-655.

Martinez, J. G., Soler, J. J., Soler, M., Møller, A. P. \& Burke, T. 1999. Comparative population structure and gene flow of a brood parasite, the great spotted cuckoo (Clamator glandarius), and its primary host, the magpie (Pica pica). Evolution, 53, 269-278.

Mennill, D. J., Ratcliffe, L. M. \& Boag, P. T. 2002. Female eavesdropping on male song contests in songbirds. Science, 296, 873

Mitton, J. B., Schuster, W. S. F., Cothran, E. G. \& Defries, J. C. 1993. Correlation between the individual heterozygosity of parents and their offspring. Heredity, 71, 59-63.

Mountjoy, D. J. \& Lemon, R. E. 1996. Female choice for complex song in the European starling: a field experiment. Behavioral Ecology and Sociobiology, 38, 65-71.

Møller, A. P. 1998. Sperm competition and sexual selection. In: Sperm Competition and Sexual Selection (Ed. by T. R. Birkhead \& A. P. Møller), pp. 55-90. London: Academic Press.

Møller, A. P., Nielsen, J. T. \& Garamszegi, L. Z. 2006. Song post exposure, song features, and predation risk. Behavioral Ecology, 17, 155-163.

Neff, B. D. \& Pitcher, T. E. 2005. Genetic quality and sexual selection: an integrated framework for good genes and compatible genes. Molecular Ecology, 14, 19-38.

Nemeth, E. 1994. Individual recognition of song by the female and song activity of the male in the reed bunting (Emberiza schoeniclus). Journal für Ornithologie, 135, 217-222.

Nemeth, E. 1996. Different singing styles in mated and unmated reed buntings Emberiza schoeniclus. Ibis, 138, 172-176.

Nicholson, J. S., Buchanan, K. L., Marshall, R. C. \& Catchpole, C. K. 2007. Song sharing and repertoire size in the sedge warbler, Acrocephalus schoenobaenus: changes within and between years. Animal Behaviour, 74, 1585-1592.

Nottebohm, F. \& Nottebohm, M. E. 1978. Relationship between song repertoire and age in the canary. Zeitschrift für Tierpsychologie, 46, 298-305.

O'Malley, S. L. 1993. Mating behaviour and reproductive success in the reed bunting Emberiza schoeniclus. Ph.D. thesis, University of Leicester.

Otter, K., Chruszcz, B. \& Ratcliffe, L. 1997. Honest advertisement and song output during the dawn chorus of black-capped chickadees. Behavioral Ecology, 8, 167-173.

Pasteau, M., Nagle, L. \& Kreutzer, M. 2004. Preferences and predispositions for intrasyllabic diversity in female canaries (Serinus canaria). Behaviour, 141, 571-583. 
Petrie, M. \& Kempenaers, B. 1998. Extra-pair paternity in birds: explaining variation between species and populations. Trends in Ecology \& Evolution, 13, 52-58.

Poesel, A., Dabelsteen, T. \& Pedersen, S. B. 2004. Dawn song of male blue tits as an indicator of competitiveness in singing interactions. Acta Ethologica, 6, 65-71.

Poesel, A., Kunc, H. P., Foerster, K., Johnsen, A. \& Kempenaers, B. 2006. Early birds are sexy: male age, dawn song and extrapair paternity in blue tits, Cyanistes (formerly Parus). caeruleus. Animal Behaviour, 72, 531-538.

Reid, J. M., Arcese, P., Cassidy, A., Hiebert, S. M., Smith, J. N. M., Stoddard, P. K., Marr, A. B. \& Keller, L. F. 2004. Song repertoire size predicts initial mating success in male song sparrows, Melospiza melodia. Animal Behaviour, 68, 1055-1063.

Reid, J. M., Arcese, P., Cassidy, A., Marr, A. B., Smith, J. N. M. \& Keller, L. F. 2005. Hamilton and Zuk meet heterozygosity? Song repertoire size indicates inbreeding and immunity in song sparrows (Melospiza melodia). Proceedings of the Royal Society of London, Series B, 272, 481-487.

Seidelmann, P. K. 1992. Explanatory Supplement to the Astronomical Almanac. Washington D.C.: University Science Books

Sexton, K., Murphy, M. T., Redmond, L. J. \& Dolan, A. C. 2007. Dawn song of eastern kingbirds: intrapopulation variability and sociobiological correlates. Behaviour, 144, 1273-1295.

Sheldon, B. C. 1994. Male phenotype, fertility, and the pursuit of extra-pair copulations by female birds. Proceedings of the Royal Society of London, Series B, 257, 25-30.

Simpson, E. H. 1949. Measurement of diversity. Nature, 163, 688.

Slabbekoorn, H. 2004. Singing in the wild: the ecology of birdsong. In: Nature's Music: The Science of Birdsong (Ed. by P. Marler \& H. Slabbekoorn), pp. 178-205. San Diego: Elsevier.

Snow, D. W. 1994. Reed bunting Emberiza schoeniclus: voice. In: Birds of the Western Palearctic vol. IX (Ed. by S. Cramp \& C. M. Perrins), pp. 285-287 Birds of the Western Palearctic. Oxford: Oxford University Press.

Spencer, K. A., Wimpenny, J. H., Buchanan, K. L., Lovell, P. G., Goldsmith, A. R. \& Catchpole, C. K. 2005. Developmental stress affects the attractiveness of male song and female choice in the zebra finch (Taeniopygia guttata). Behavioral Ecology and Sociobiology, 58, 423-428.

Suter, S. M., Keiser, M., Feignoux, R. \& Meyer, D. R. 2007. Reed bunting females increase fitness through extra-pair mating with genetically dissimilar males. Proceedings of the Royal Society of London, Series B, 274, 2865-2871.
Thomas, R. J. 2002. The costs of singing in nightingales. Animal Behaviour, 63, 959-966.

Thomas, R. J. \& Cuthill, I. C. 2002. Body mass regulation and the daily singing routines of European robins. Animal Behaviour, 63, 285-292.

Ward, S. \& Slater, P. J. B. 2005. Raised thermoregulatory costs at exposed song posts increase the energetic cost of singing for willow warblers Phylloscopus trochilus. Journal of Avian Biology, 36, 280-286.

Ward, S., Speakman, J. R. \& Slater, P. J. B. 2003. The energy cost of song in the canary, Serinus canaria. Animal Behaviour, 66, 893-902.

Weatherhead, P. J. \& Yezerinac, S. M. 1998. Breeding synchrony and extra-pai mating in birds. Behavioral Ecology and Sociobiology, 43, 217-219.

Webster, M. S., Pruett-Jones, S., Westneat, D. F. \& Arnold, S. J. 1995. Measuring the effects of pairing success, extra-pair copulations and mate quality on the opportunity for sexual selection. Evolution, 49, 1147-1157.

Webster, M. S., Tarvin, K. A., Tuttle, E. M. \& Pruett-Jones, S. 2007. Promiscuity drives sexual selection in a socially monogamous bird. Evolution, 61, 2205-2211.

Welling, P., Koivula, K. \& Lahti, K. 1995. The dawn chorus is linked with female fertility in the willow tit Parus montanus. Journal of Avian Biology, 26, 241-246.

Westneat, D. F. \& Sherman, P. W. 1997. Density and extra-pair fertilizations in birds: a comparative analysis. Behavioral Ecology and Sociobiology, 41, 205-215.

Wetton, J. H. \& Parkin, D. T. 1991. An association between fertility and cuckoldry in the house sparrow, Passer domesticus. Proceedings of the Royal Society of London, Series B, 245, 227-233.

Whittingham, L. A. \& Dunn, P. 0. 2005. Effects of extra-pair and within-pair reproductive success on the opportunity for selection in birds. Behavioral Ecology, 16, 138-144.

Wingelmaier, K., Winkler, H. \& Nemeth, E. 2007a. Reed bunting (Emberiza schoeniclus) males sing an 'all-clear' signal to their incubating females. Behaviour, 144, 195-206.

Wingelmaier, K., Winkler, H. \& Nemeth, E. 2007b. Mating behavior of reed buntings (Emberiza schoeniclus) in captivity. Wilson Journal of Ornithology, 119, 463-466.

Zahavi, A. \& Zahavi, A. 1997. The Handicap Principle: A Missing Piece of Darwin's Puzzle. Oxford: Oxford University Press. 